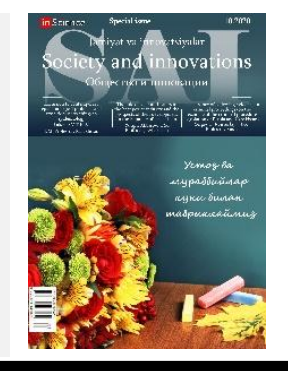

\title{
Automated system for monitoring the development and spread of forest crop pests
}

\section{Khashim YAKHYAEV ${ }^{1}$ Zafar Nafasov $^{2}$}

${ }^{1}$ Uzbek research institute of plant protection

\section{ARTICLE INFO}

\section{Article history:}

Received 10 august 2020

Received in revised form

20 august 2020

Accepted 25 august 2020

Available online

August 2020

\section{Keywords:}

Monitoring system

Forestry crops

Pests

Database

Algorithm

Program

Summary tables.

\begin{abstract}
An automated monitoring system has been developed for the AFM "Protection" of the development and spread of pests of forestry crops. The system is designed in the form of a local computer network, operates on-line and has the following additional features: automatic integration of daily data required for services of regional departments and the Forestry Agency of the republic. Based on these data, weekly, monthly maps and summary tables will be compiled.

2181-1415/@ 2020 in Science LLC.

This is an open access article under the Attribution 4.0 International (CC BY 4.0) license (https://creativecommons.org/licenses/by/4.0/deed.ru)
\end{abstract}

\section{SUMMARY}

In the main directions of sustainable development of forestry in the Republic of Uzbekistan at the present stage for the period up to 2030, it is envisaged to further increase the productivity of forests on the basis of technical re-equipment, the introduction of advanced techniques to increase the efficiency of forestry production, improve the protection of forests from fires and protect them from pests and diseases. According to the forestry agency of the Republic of Uzbekistan, the area of forest plantations is 3.2 million hectares. This is about $7 \%$ of the total area of the republic. Of these, 821.0 thousand hectares are forest plantations. This means that only $2 \%$ of the area is covered by forests.

When planning the necessary forest protection measures, it is required to identify complexes of the most important, most dangerous pest species and predict further changes in the

\footnotetext{
${ }^{1}$ DSc, professor, Uzbek research institute of plant protection

email: yaxashm@mail.ru

$2 \mathrm{PhD}$, senior researcher, Uzbek research institute of plant protection

email: nafasov85@gmail.ru
} 
number of pest populations. Therefore, when organizing a monitoring system, it is necessary to obtain reliable information about the level of the number of pests and the degree of their threat to crops and plantations. First, when organizing a systematic system of forestry monitoring, the territory should be zoned based on economic and ecological criteria. Secondly, due to the fact that the emergence of foci of mass reproduction of pests is usually confined to regions where critical weather situations are observed, then when designing forestry monitoring such areas should be given priority attention. Thirdly, it is necessary to strongly recommend the organization of stationary objects in all farms, which will annually assess the level of abundance, the qualitative state of the populations of the main species and the state of the growing stand.

In case of significant damage to forest stands, a detailed survey with an assessment of the dynamics of tree mortality, determination of the qualitative and quantitative characteristics of the dominant pest species and the development of a strategy for forest protection measures should be carried out by specialists-entomologists.

\section{Ўрмон дарахтлари зарарли организмларини тарқалиши ва ривожланишининг автоматлаштирилган мониторинг}

\section{ТИЗИМи}

\section{Калит сўзлар:}

Мониторинг тизими

Ўрмон хўжалиги экинлари

Зарарли организмлар

Маълумотлар базаси

Алгоритм

Дастур

Маълумотлар жадвали.

\section{АННОТАЦИЯ}

Ўрмон дарахтлари зарарли организмларининг
тарқалиши ва ривожланишини химояловчи автоматлаштирилган мониторинг тизими АMT ишлаб чиқилди. Тизим локал компьтер тўри кўринишида расмийлаштирилган, диалог режимида фаолият олиб боради хамда Республика ўрмон хўжалиги қўмитаси ва вилоят бошқармалари учун зарур бўлган кунлик маълумотларни автоматик бирлаштириш имкониятига эга. Бу маълумотлар асосида хар ўнкунлик, хар ойлик хариталар ва маълумотлар жадваллари тузилади.

\section{Автоматизированная система мониторинга развития и распространения вредных организмов лесохозяйственных культур}

\section{Ключевые слова:}

Система мониторинга

Лесохозяйственные

культуры

Вредные организмы

База данных

Алгоритм

\section{АННОТАЦИЯ}

Разработана автоматизированная система мониторинга ACM «Защита» развития и распространения вредных организмов лесохозяйственных культур. Система оформлена в виде локальной компьютерной сети, функционирует на диалоговом режиме и имеет следующие дополнительные возможности: автоматическое 
Программа

Сводные таблицы. объединение ежедневных данных, необходимых для служб областных управлений и Агентству лесного хозяйства республики. На основании этих данных будут составлены ежедекадные, ежемесячные карты и сводные таблицы.

При планировании необходимых лесозащитных мероприятий требуется выявить комплексы главнейших, наиболее опасных видов вредителей и спрогнозировать дальнейшие изменения численности популяций вредителей. Поэтому при организации системы мониторинга необходимо получить достоверную информацию об уровне численности вредителей и степени их угрозы посевам и насаждениям. Во-первых, при организации планомерной системы лесохозяйственного мониторинга следует районировать территорию на основе хозяйственно-экологических критериев. Во-вторых, в связи с тем, что возникновение очагов массового размножения вредителей приурочено, как правило, к регионам, где наблюдаются критические погодные ситуации, то при проектировании лесохозяйственного мониторинга таким районам следует уделять первоочередное внимание. В-третьих, необходимо настоятельно рекомендовать организацию стационарных объектов во всех хозяйствах, в которых ежегодно будет производиться оценка уровня численности, качественного состояния популяций главнейших видов и состояния древостоя.

При значительном повреждении древостоев детальное обследование с оценкой динамики отпада деревьев, определением качественных и количественных характеристик доминирующих видов вредителей и разработкой стратегии проведения лесозащитных мероприятий должно быть проведено специалистами-энтомологами.

Кроме того, зачастую довольно большое затруднение вызывает получение метеоданных за несколько лет до вспышки массового размножения, что необходимо для детального анализа погодной ситуации в годы, предшествующие редкому изменению численности вредителей. Поэтому, для слежения за динамикой погодной ситуации можно рекомендовать установку на территории лесничеств элементарных метеорологических приборов, регистрирующих ход изменения температуры, количества выпадающих осадков и скоростей ветра.

Важной задачей при разработке систем мониторинга является проектирование информационного обеспечения, которое должно охватить всю совокупность информации в системе, а также способы ее представления, хранения и обработки. Проектирование информационного обеспечения является сложным и самостоятельным этапом разработки информационных систем $[1,2,4]$.

В $[3,5]$ выделены следующие основные задачи, возникающие при создании информационного обеспечения:

- определение состава данных, необходимых для решения комплекса задач и определения видов и объемов данных;

- формализация представления информации - выбор ее структуры и способов представления;

- разработка форм входной и выходной документации;

- выбор и обоснование носителей информации;

- разработка классификаторов и кодификаторов данных;

- разработка способов накопления, обновления и поиска в массивах данных; 
- разработка информационных языков общения пользователя с вычислительной техникой.

С учетом вышеизложенного разработана автоматизированная система мониторинга «Защита» (АСМ «Защита») развития и распространения основных вредителей лесохозяйственных культур (блок-схема АСМ «Защита» приведена на рис. 1). Информация о вредных объектах лесохозяйственных культур и проведенных защитных мероприятий в областных управленияхлесного хозяйства с помощью модемов поступает в центральный компьютер, находящийся в Узбекском республиканском агентстве лесного хозяйства. Эту информацию передают сотрудники областных управлений на основе имеющихся инструкций. В центральном компьютере эти данные обрабатываются и составляются карты в разрезе областей республики. Затем, на основе данных о погодных условиях, поступающих из гидрометслужбы, разрабатываются прогнозы развития вредных объектов, которые будут передаваться обратно в областные управления лесного хозяйства. Таким образом, система мониторинга содержит в разрезе районов и областей республики ежедневные, ежедекадные, ежемесячные и ежегодные данные о развитии вредных организмов; данные по зараженным и обработанным площадям лесохозяйственных культур. На основании этих данных будут составлены ежедекадные, ежемесячные карты и сводные таблицы, отражающие обзор развития и распространения основных вредных организмов (фрагмент работы системы и выдачи карт приведена на рис.2).

ACM «Защита» оформлена в виде локальной компьютерной сети, функционирует на диалоговом режиме и имеет следующие дополнительные возможности: автоматическое объединение ежедневных данных, необходимых для служб областных управлений и Агентству лесного хозяйства республики, для составления обзора развития и распространения вредных объектов; поисковую библиографию ссылок по основным вредным объектам лесных культур.

Данные по вредным объектам и окружающей среде, введенные в систему используются для составления ежемесячных карт, отражающих развитие вредных объектов, их распространение или отсутствие, места проведения химических и биологических обработок и соответствующую экологическую информацию. Составленные карты дают возможность показать информацию по основным вредным объектам сельскохозяйственных культур за предыдущий, текущий и следующий месяцы, с использованием принятых символов, а также в виде диаграмм и графиков. Данные дисплея показывают последовательность событий за определенный период и могут быть использованы для автоматического сравнения статистики обследованных и обработанных земель по основным вредным объектам, а также условий окружающей среды.

В заключение необходимо отметить, что внедрение АСМ «Защита» предоставит Агентству лесного хозяйства республики Узбекистан следующие возможности:

- получение и сохранение детальных данных по мониторингу и химическим и биологическим обработкам против вредных организмов, а также данных по окружающей среде;

- быструю обработку данных по вредным объектам с помощью простого в пользовании дисплея; 
- содержание географического справочника обследованных мест для более точной базы данных по вредным объектам;

- автоматическое извлечение ключевой информации, используемой для принятия оперативных решений и планирования защитных мероприятий против вредных объектов на областном и республиканском уровнях;

- прогнозирование вспышек вредных объектов на кратко, средне и долгосрочный периоды на основе их мониторинга, экологических и других основополагающих данных;

использование системы как государственного архива по вредным объектам для последующих научных исследований.

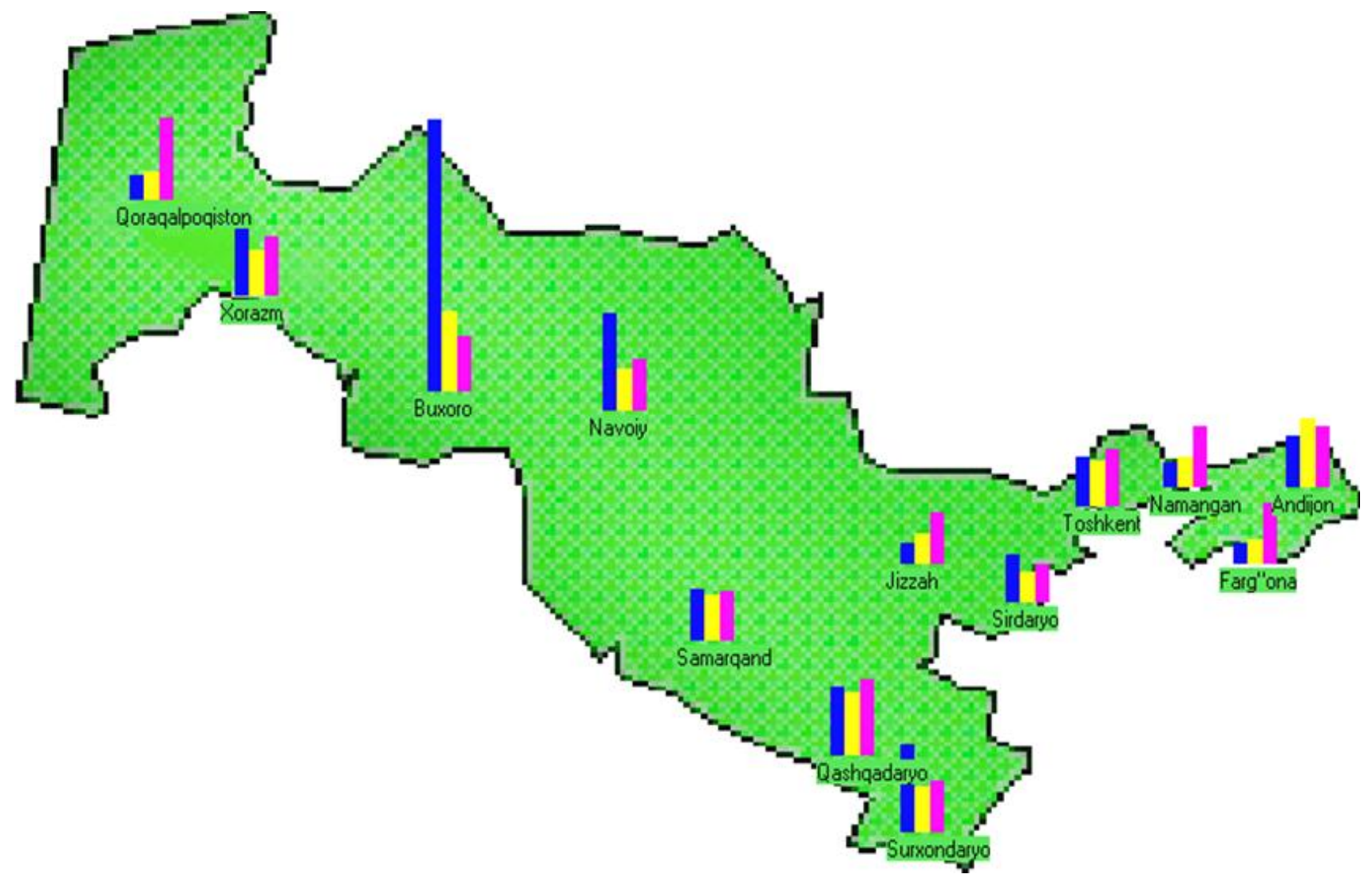

Рис. 1. Вид карты,отражающей обзор развития и распространения основных вредных организмов лесохозяйственных культур 


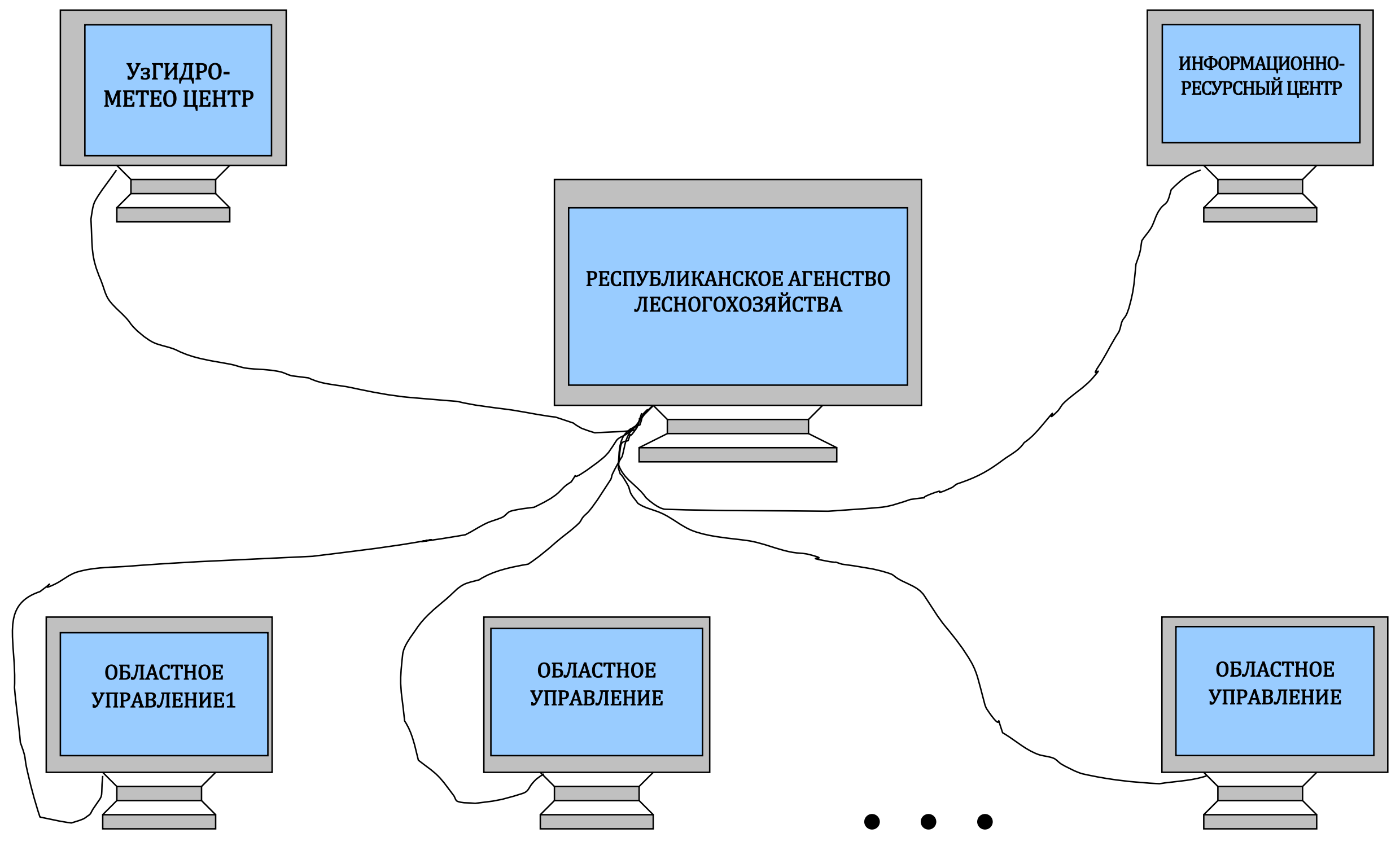

Рис. 2. Блок-схема АСМ «Защита» 


\section{Библиографический список}

1. Поляков И.Я. Экологический мониторинг в защите растений и принципы его автоматизации / В кн.: «Пути автоматизации фитосанитарной диагностики». - Л., изд-во ВИЗР. 1985. - С. 7-15.

2. Санин С.С., Макарова А.А. Биологические, агроэкологические аспекты фитосанитарного мониторинга. // Вестник защиты растений, - СПб, Пушкин, 1999, - № 1, - С. 62-66.

3. Хохлачева Г., Пендер Д. Казахстанская информационная система борьбы с саранчовыми (КИСБС) // Защита и карантин растений в Казахстане. 2003. - № 1. - С. 15-19.

4. Яхяев Х.К. Разработка научных основ автоматизации прогнозирования и управления вредными объектами сельскохозяйственных культур: Дисс. на соис. уч. степ.док. с.-х. наук. - Ташкент, 1994, -291 с.

5. Яхяев Х.К., Холмурадов Э.А., Вафоев А.К. Экологический мониторинг и прогноз - основа защиты растений (обзорная информация). - Ташкент, 2005, $56 \mathrm{c}$. 